\title{
Corrigendum: Parental Attunement, Insightfulness, and Acceptance of Child Diagnosis in Parents of Children With Autism: Clinical Implications
}

\author{
Magda Di Renzo ${ }^{1 *}$, Viviana Guerriero ${ }^{1,2}$, Giulio Cesare Zavattini ${ }^{2}$, Massimiliano Petrillo ${ }^{1}$, \\ Lidia Racinaro $^{1}$ and Federico Bianchi di Castelbianco ${ }^{1}$ \\ ${ }^{1}$ Institute of Orthophonology (IdO), Rome, Italy, ${ }^{2}$ Department of Dynamic and Clinical Psychology, Sapienza University of \\ Rome, Rome, Italy
}

Keywords: parental attunement, insightfulness, acceptance of child diagnosis, autism spectrum disorders, parent-child interaction

\section{OPEN ACCESS}

Approved by:

Frontiers Editorial Office,

Frontiers Media SA, Switzerland

${ }^{*}$ Correspondence

Magda Di Renzo

m.direnzo@ortofonologia.it

Specialty section:

This article was submitted to Psychology for Clinical Settings,

a section of the journal

Frontiers in Psychology

Received: 10 August 2020

Accepted: 12 August 2020

Published: 15 September 2020

Citation:

Di Renzo M, Guerriero V, Zavattini GC

Petrillo $M$, Racinaro $L$ and Bianchi di Castelbianco F (2020) Corrigendum:

Parental Attunement, Insightfulness, and Acceptance of Child Diagnosis in Parents of Children With Autism:

Clinical Implications.

Front. Psychol. 11:593327.

doi: 10.3389/fpsyg.2020.593327

\section{A Corrigendum on}

Parental Attunement, Insightfulness, and Acceptance of Child Diagnosis in Parents of Children With Autism: Clinical Implications

by Di Renzo, M., Guerriero, V., Zavattini, G. C., Petrillo, M., Racinaro, L., and Bianchi di Castelbianco, F. (2020). Front. Psychol. 11:1849. doi: 10.3389/fpsyg.2020.01849

In the original article, there was an error. The acronym "D.E.R.B.B.I. intervention" was expanded to "Development Emotional Relation Body-Based Intervention".

An error was also made, referring to "the Institute of -Blinded for Peer Review-"

A correction has been made to Conclusion, Paragraph Number 1:

The results presented in this study provide some insights into potential clinical work with the mothers and fathers of children with ASD. Studying the parental ability of insightfulness and acceptance of a child diagnosis of ASD has enriched our understanding of the processes underlying the interactions of these parents with their children. These aspects should be addressed through intervention programs for parents. At the Institute of Orthophonology (IdO) support for parents has been incorporated into the D.E.R.B.B.I. intervention (known in full as the Developmental, Emotional Regulation and Body-Based Intervention) within the Turtle Project (Di Renzo et al., 2016). The project combines various interventions offered to children and parents including child assessment (Di Renzo et al., 2019), counseling for parents, clinical sessions with the professionals who work with the child, thematic seminars and experiential workshops, mothers/fathers-child in care settings, and groups of parents (Di Renzo et al., 2020a).

The authors apologize for this error and state that this does not change the scientific conclusions of the article in any way. The original article has been updated. 


\section{REFERENCES}

Di Renzo, M., Bianchi di Castelbianco, F., Vanadia, E., Petrillo, M., Racinaro, L., and Rea, M. (2016). From the emotional integration to the cognitive construction: the developmental approach of Turtle Project in children with Autism Spectrum Disorder. Autism 6, 1-9. doi: 10.4172/2165-7890.100 0160

Di Renzo, M., Guerriero, V., Mammarella, V., and Bianchi di Castelbianco, F. (2020a). "Developmental interventions for children with Autism Spectrum Disorders: a literature review," in Understanding Children with Autism Spectrum Disorders, ed. B. Anne (Nova Book Publisher), $57-105$.
Di Renzo, M., Guerriero, V., Petrillo, M., Racinaro, L., Vanadia, E., and Bianchi di Castelbianco, F. (2019). A comprehensive assessment process for children with autism spectrum disorders. Advances in Autism 6, 95-108. doi: 10.1108/AIA-09-2018-0031

Copyright (๑) 2020 Di Renzo, Guerriero, Zavattini, Petrillo, Racinaro and Bianchi di Castelbianco. This is an open-access article distributed under the terms of the Creative Commons Attribution License (CC BY). The use, distribution or reproduction in other forums is permitted, provided the original author(s) and the copyright owner(s) are credited and that the original publication in this journal is cited, in accordance with accepted academic practice. No use, distribution or reproduction is permitted which does not comply with these terms. 